was torn about 6 in. from the placental end. The child had breathed.

This case is interesting inasmuch as barely three hours had elapsed from the time labour had commenced to the time the concealment of the birth was bronght to light. Although the mother must have lost an enormons amount of blood, as evidenced by the state of the room and her linen, and notwithstanding the fact that she was removed to the union the next morning, a distance of two miles, she is now quite well.

West Malling, Kent.

\section{A CASE OF GUMMA INSIDE THE STERNUM.}

By Thomas Cole, M.D., F. R.C.P.Lond.,

IATE SENIOR PHYSICIAN TO THE ROYAL UNITED HOSPITAI, BATH.

I WAS a few years ago asked by his two medical attendants to see a man, aged about forty-eight years. He had been indefinitely ill for some time, suffering from dyspncea, slight congh, and some blueness. The most minute examination of every organ revealed nothing, but I found on the front of the sternum a small boss or elevation which was a third of an inch wide and about the same in elevation. The mass was slightly tender. I was the first to discover it. I also thought the substernal respiration was somewhat more tracheal than usual. Taking the few facts into consideration I suggested that there might be some gummatous mischief and advised the administration of $20 \mathrm{gr}$. of iodide of potassinm every four hours. But I could make no impression on my friends, who would express no opinion, and only (when I was gone) put eight leeches over the little swelling. In two or three days we met again. The mass was rather larger, there was a little more dyspncea, the respiration was noisy, and there was a slight laryngeal congh I still urged my plan; it could do no harm and might confer immense benefit on the patient, whose case I began to think of with great distrust. Bat I could not move these practitioners by any argument whatever. Still they believed in me and on many occasions had called me in. They wished me to meet them again in a week, which of course I did. The poor fellow was evidently gradually slipping through their fingers; every symptom was worse, intra-sternal pressure was more marked, and renous stasis above the clavicles was developing. I asked, "Are you prepared to go on treating this case as you are-doing nothing?" One of them said, "Are you prepared to give us a good reason for such heroic treatment as the administration of $20 \mathrm{gr}$. of jodide of potassinm every two or three hours" (which I then proposed)? A merciful providence intervened on the patient's behalf as well as on my own. Strange, indeed, was it that the left sleeve of his night-dress being unbuttoned and drawn up towards the elbow I saw a large node on the ulna at least $2 \frac{1}{2}$ in. by $1 \frac{1}{2}$ in. I pointed it out to my sceptical friends and turning to the patient said: "How long have you found this?" "It was not there, Dr. Cole, when you last came, but the day after it began to come and it is getting very painful. I intended to call your attention to it this morning as I knew you were all coming and you had asked about swellings before." Persuasion leaped into the minds of my friends after so nnmistakeable a proof of the nature of the malady and the treatment was at once begun. In a very short time all the evidence vanished and the patient resumed his usual health. Of course, he was most carefully watched and when I heard of his state a year afterwards he was well and free from disease. Does not such a case prove to every practitioner the absolnte necessity of an accurate diagnosis in every case which comes under his notice? How many lives would be saved were common care taken in such important and critical matters?

Bath.

\section{NOTES ON TWO CASES OF CONGENITAL ABSENCE} OF THE RIGHT EYE (ANOPHTHALMOS).

By John R. Rolston, L.R.C.P. EpIn., M.R.C.S. ENG , GURGHON TO THE ROYAL EYE INFIRMART, PLYMOUTH, AND OPHTHALMIO SURGBON TO THE ROYAL ALBERT HOSPITAL, DEVONPORT.

IN THe LANCET of Jan. 1st, 1898, Mr. W. G. Nash of Bedford records a case of Congenital Absence of the Right Wye, with an illustration. As I have seen two cases of the same deformity-one of which very closely resembles the case related by Mr. Nash-I thought an account of them would interest the readers of TII LANCET. The accom panying illustration is reproduced from a photograph of thes one which is so similar to that described by Mr. Nash.

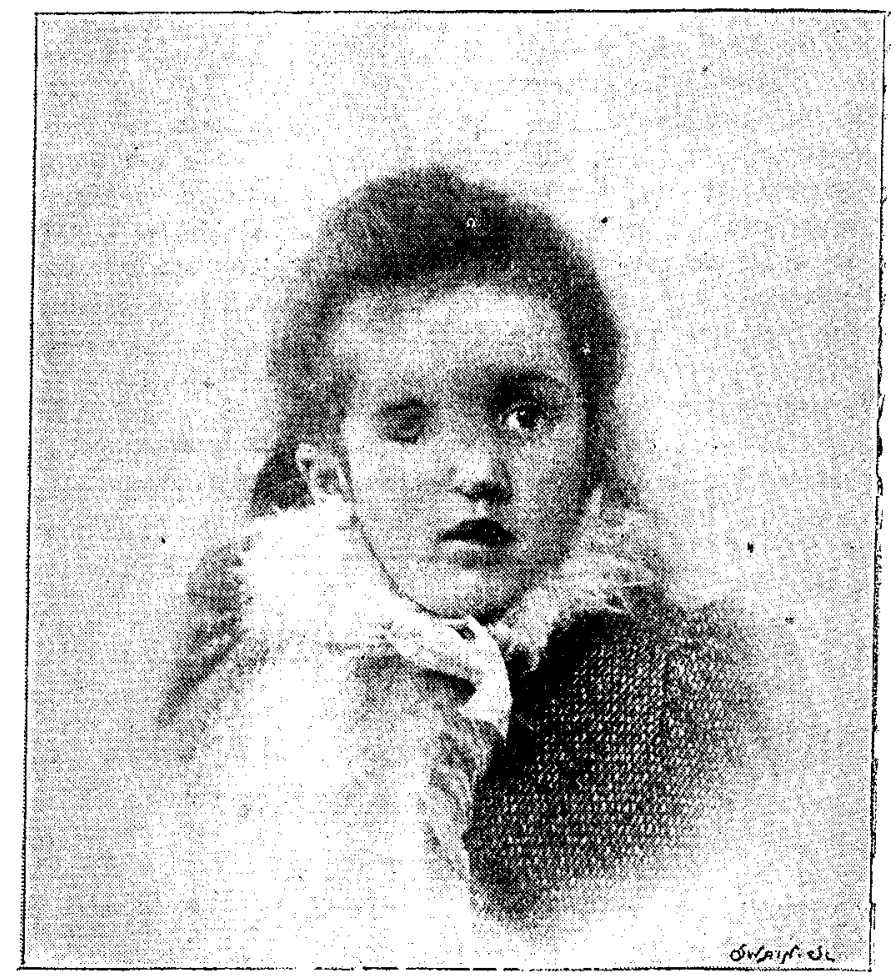

Portrait of the patient (aged six years) in Case 1.

CASE 1.-A girl, aged six years, was brought to me in December, 1896. There was-as is depicted in the illustration-congenital absence of the right globe with a smals rudimentary palpebral aperture $12 \mathrm{~mm}$. long with eyelashes; a small carancle was seen inside. No evidence of a rudimentary globe was observed. There was much flattening of the bridge of the nose and the right ala of the nose was imperfectly developed. The left eye had horizontal nystagmus. The mother has had 5 children, all of whom are healthy. She has had no miscarrlage. She says that she had a fall several months before the child was born.

CAsE 2.-A girl, aged six years, was brought to me in December, 1896. There was congenital absence of the right eye with a small but otherwise natural palpebral aperture $19 \mathrm{~mm}$. long. The cavity seemed to be natural. There was no sign of a rudimentary globe. No defect of the face was present. In this case the mother was not seen by me and no family history could be obtained. Photography was not allowed. The left eye was normal.

I am of opinion that these two cases may be correctly classified as true anophthalmos, as in each case I failed to find any rudimentary globe (although I did not use dissection), and this class is much more rare than that to which should imagine Mr. Nash's belongs- - iz., that of microphthalmos, as he states that "a small pigmented body about. the size of a pea occupied the centre of the cavity" of the orbit. The point in common is that in all three cases the right side is affected.

Plymouth.

\section{NOTE ON A CASE OF FATAL HEART AFFECTION IN SCARLATINAL RHEUMATISM.}

By Frank RoBINSON, M.D. VICT.,

RHSIDENT MEDICAI OTFICER, CITY HOSPITAL NORTH, LIVERPOOZ.

I BELIEVE that the following case of acute pericarditis (largely obliterative) will be of interest in connexion with the: annotation on obliterative pericarditis in THH LANCET of June 18tb, 1898.

A girl, aged ten years, suffered from an attack of scarlet. fever of average severity in the City Hospital North, Liverpool, and made a satisfactory recovery from the acute stage. On the twenty-first day a mild attack of articulaz rheumatism commenced. There was no local swelling and but little pyrexia occurred, but the wandering pains persisted and on the fiftieth day severe pain drew special attention to the hort. An extensive area of pericardial 